\title{
Study on the Radio Regulations of the ITU Radio Regulations Institutions and Developed Countries Before and After Regulations
}

\author{
Sang-Ok Youn ${ }^{1}$ and Hyun-sik Shin ${ }^{2}$ \\ ${ }^{1}$ Ssangyong software CO., LTD \\ ${ }^{2}$ Department of Electronic Communication Engineering, Chunnam National \\ University \\ ysangok@nate.com,dol27@naver.com
}

\begin{abstract}
There propagate use management paradigm in developed countries is changing as Command \& Control $\Rightarrow$ Market Based $\Rightarrow$ Open Access $\Rightarrow$ Manage By Technology \& Technical Analysis, that the policy response to environmental changes, such as a variety of new technologies. The emergence of service, the proliferation of propagation users It is to activate the market. However, the basic principles of radio management such that the change of paradigm be used to spread in a range that does not affect the interference, such as the horn is to be observed. Around the world in order to prevent the propagation and utilization Horn interference enacted regulations for managing the radio station, and also discipline.
\end{abstract}

Keywords: Radio Regulations, radio control, radio station, also permit system, reporting system, inspection system

\section{Introduction}

In the International Telecommunication Union (ITU) Radio Regulation, electromagnetic waves are defined as frequencies below $3000 \mathrm{GHz}$ that spread into space without artificial induction, and Korea follows international definitions. Propagation is an electromagnetic wave that propagates in space without artificial induction and has a frequency within the range defined by ITU. The frequency of the dual service is up to $300 \mathrm{GHz}$. Of the distributed frequencies, more than $90 \%$ of the daily frequency band we contact daily is less than $3 \mathrm{GHz}$. Anyone can generate radio waves by transmitting equipment, but it can occur indefinitely without depletion. However, if frequency propagation is used in the same time and space, horn interference occurs and radio wave resources become unavailable. Due to the physical limitations of such use, Korea has enacted radio control laws for the first time in 1961 to allow the state to manage radio resources and to use radio waves only when granted rights.

\section{ITU (International Telecommunication Union) RR Regulation}

\subsection{Radio Resource Management}

Radio station licenses stipulate that not all radio stations can operate without the license issued by the competent administration or government entrusted authority, and they include the obligation to inspect radio waves for efficient management of radio resources.

Inspection 1 of a radio station shall observe the technical characteristics of a radio station specified in the Radio Regulations, including the frequency tolerance of radio 
waves used in a radio station, spurious emission power, and allowable power level, in order to ensure efficient use of frequency.

Table 1. Test Items of Measuring Equipment

\begin{tabular}{l|l}
\hline Measuring Equipment & Measuring parameters \\
\hline $\begin{array}{l}\text { Spectrum analyzer / measurement } \\
\text { receiver }\end{array}$ & $\begin{array}{l}\text { Frequency, bandwidth, jeonge intensity, harmonics, } \\
\text { intermodulation enemy, Spurious }\end{array}$ \\
\hline $\begin{array}{l}\text { Signal analyzers, antennas } \\
\text { Frequency meter }\end{array}$ & $\begin{array}{l}\text { Frequency bandwidth, power, harmonics, } \\
\text { intermodulation enemy, spurious, modulation }\end{array}$ \\
\hline $\begin{array}{l}\text { Meter, directional coupler, load } \\
\text { resistance }\end{array}$ & Frequency and frequency deviation \\
\hline $\begin{array}{l}\text { Calibrated antenna / field strength } \\
\text { meter }\end{array}$ & Field strength \\
\hline The power flux density meter & Electrical, magnetic and electromagnetic field strength \\
\hline $\begin{array}{l}\text { Modulation Analysis } \\
\text { Remote meter and odometer, tape } \\
\text { measures }\end{array}$ & $\begin{array}{l}\text { Mediated modulation of a specific signal type variables, } \\
\text { and additional signals }\end{array}$ \\
\hline Compass & Antenna height and distance \\
\hline GPS & A station location \\
\hline
\end{tabular}

Radio station check 2 shall take measures to eliminate interference by minimizing power copying, distress and interference with safety frequencies, occupied bandwidth and spurious emissions from all stations of all stations. Inspection of aircraft and ship stations shall be conducted by each country to check the adequacy of the radio facilities and radio installations of aircraft stations and ship stations.

\subsection{Interference Prevention Management}

Propagation uses the same frequency band at the same time and space and has a physical characteristic (3 million $\mathrm{km}$ of free space propagation per second) that determines the range of the space according to the transmitter output. Due to these characteristics, if there are effects such as inter-country propagation menstrual period and horn interference, it may cause communication disorder and other accidents. The use management paradigm is changing from Command \& Control $\Rightarrow$ Market Based $\Rightarrow$ OpenAccess $\Rightarrow$ Manage By Technology \& Technical Analysis for the policy response and market revitalization of environment change such as the emergence of various new technologies and services, to be.

\subsection{Management for Market-Based Effective Use of Radio Waves}

The fundamental principle of radio management should be observed that radio waves should be used within a range that does not affect the paradigm change, such as interference.

In order to prevent the effective use of radio waves and horn interference, countries around the world have legislated and regulated radio control regulations that are appropriate for their own countries.

\subsection{Smooth Introduction of New Technology Services}

New technologies such as Underlay / Overlay have been introduced to efficiently utilize shortage of radio resources as the use of radio waves, such as the use of compact, 
low power radio devices, has increased rapidly. Preliminary research and management of interference and interference suppression are also required for effective use of radio waves such as white space and UWB (Ultra-wideband, 3.1 to $4.8 \mathrm{GHz}, 7.2$ to $10.2 \mathrm{GHz}$ ) sharing the frequency band.

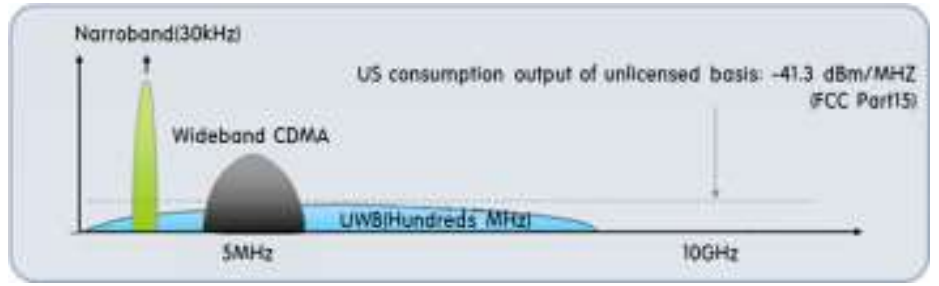

Figure 1. Underlay the Propagation of UWB Use Cases Services

\subsection{ITU's Radio Station and Wireless Business Classification System}

The ITU RR regulations define a total of 41 tasks, including 21 defined tasks as defined for the wireless communications task and 20 defined tasks as a subset of the task. The five tasks of the mobile service, the mobile-satellite service, the radiodetermination service, the radiodetermination-satellite service, and the earth exploration.The wireless communication service is defined as a service that includes transmission, emission (emission, copying), and reception of radio waves for the purpose of specific telecommunication.

At this time, all tasks not mentioned in the RR are called ground operations. A radio station is a combination of one or more transmitters (or receivers) or transmitters and receivers, including the necessary accessories in one place in order to perform radio communications services or radio astronomy services.

Each station is classified by its permanent or temporary operation. A total of 37 countries are defined, including 18 national stations defined as radio stations and 19 radio stations redefined on the lower level of the corresponding station.In the RR of ITU, the radio services and stations are stipulated in a system that stipulates the definition of each of the services and stations considering their mutual status.

For example, the earth station is defined as a "station", and the mobile earth station is defined as an earth station performing the mobile-satellite service for the purpose of use while it is moving or stopping at an unspecified point. The mobile earth station is divided into four sub-hierarchies, and the air earth station is defined as a mobile earth station located on the aircraft and performing the aeronautical mobile-satellite service, for example. This is very similar to the way in which broadcasting stations in Korea are defined in the Radio Law and four different types are defined in the Enforcement Ordinance of the Radio Law.

\subsection{Radio Stations In Accordance With the Radio Task in ITU-RR}

Because it is possible to verify whether a radio station is actually installed and operated according to the standard by inspection of a radio station, without checking, it is impossible to confirm whether or not the state-related matters concerning the use of the frequency permitted by the state are implemented. none. In addition, important data (such as electric field strength reference value) for spectrum monitoring cannot be secured, and there is a case where the use of the radio wave is violation or permission, and there is a problem in the spectrum management. From a behavioral point of view, if there is no inspection, it can be considered that moral hazard due to operation without inspection is generated and it is okay to ignore compliance with standards. The inspection contributes to maintaining the responsibility of the radio users so that they are able to operate in a 
state without any interference or interference by complying with national technical and administrative regulations.

In the ITU Radio Regulation (RR) regulation, the classification of a radio station is classified according to the radio service. The table below summarizes the radio stations belonging to each task by comparing the definition of the radio station and the definition of the radio station in ITU RR.

\section{Domestic Radio Management System}

\subsection{Pre-Post Regulation of Radio Stations}

Domestic stations are allowed to enter the frequency assignment method among the three frequency assignment methods (assignment, assignment, and approval) of the radio management system. The frequency designation means that the policy authority designates a specific frequency to be used by a radio station established by permission or notification(Article 2, Item 4 of the Radio Law), and permits the future creation science minister to use a specific frequency for each radio station(Article 21, Item 2 of the Radio Law).

Table 2. Dictionary of the Country Post Regulation

\begin{tabular}{|c|c|c|}
\hline Cour & Pre-regulation & Regulation \\
\hline Korea & n) & $\begin{array}{l}\text { Periodic Inspection (1-5 years), the } \\
\text { electromagnetic strength measurements, } \\
\text { radio monitoring / inspection, and } \\
\text { temporary inspection }\end{array}$ \\
\hline JSA & $\begin{array}{l}\text { Stations construction permit (Act } 319 \\
\text { trillion) environmental impact assessment } \\
\text { (Environment Assessment) } \\
\text { (General Stations) coordination duties } \\
\text { (For operators) User Community inter- } \\
\text { regional coordination obligation of the } \\
\text { installation permit, etc. }\end{array}$ & $\begin{array}{l}\text { FCC monitoring / interference Survey / } \\
\text { Inspection } \\
\text { (Biennial conducted in private ABP } \\
\text { (Alternate Broadcast Inspection Program)) } \\
\text { Periodic inspection stations }\end{array}$ \\
\hline pan & $\begin{array}{l}\text { Completion of inspection (proof of } \\
\text { appropriate technical standards for radio } \\
\text { equipment received is completed in checks } \\
\text { omitted) } \\
\text { Change tests }\end{array}$ & $\begin{array}{l}\text { Periodic Inspection (1-5 years), radio } \\
\text { monitoring / inspection, temporary } \\
\text { inspection }\end{array}$ \\
\hline Australia & $\begin{array}{l}\text { Radio stations established by private } \\
\text { operators (Accredited Persons) } \\
\text { Compliance with the } \\
\text { Communications Australian } \\
\text { installation rules (ACID) } \\
\text { Install the permission of local councils } \\
\end{array}$ & $\begin{array}{l}\text { ACMA monitoring } \\
\text { investigation } \\
\text { Random Inspection }\end{array}$ \\
\hline England & $\begin{array}{l}\text { For general-purpose stations or Site } \\
\text { Clearance Coordination conduct } \\
\text { LPA on the providers after prior approval } \\
\text { for installation work }\end{array}$ & $\begin{array}{l}\text { Ofcom monitoring / interference Survey } \\
\text { Inspection } \\
\text { Entrusted to private agencies }\end{array}$ \\
\hline
\end{tabular}

In particular, the permission for the establishment of a radio station prescribed in Article 21 of the Radio Law is examined in advance in the following 4 paragraphs, as follows: (1) whether or not the frequency specification is possible; (2) whether the radio equipment to be installed or operated is the 45th (3) whether or not the deployment plan of the radio worker is in conformity with the qualification and placement standard in accordance with Article 71 of the same Act, (4) whether or not it conforms to the opening conditions of the radio station pursuant to Article 20-2 of the same Act It is judging. 
Accordingly, in order to confirm whether the frequency can be designated for each radio station type, it is judged whether or not the compatibility with the frequency distribution table and the radio wave designation criterion is compatible, the suitability of the technical standard prescribed for each radio station type is judged, Review and authorize worker qualifications.

Regulation is divided into pre-regulation and post-regulation, and at the same time, the legal regulation of behavior regulation is divided into regulation and economic regulation. Domestic regulation level is centered on pre-regulation and legal regulation. Some are applied through collection. The use of radio waves as an economic regulation of a radio station species is applied differently depending on the radio station type, use subject, and purpose of use, which has a different legal basis from the radio station classification in Article 29 of the Enforcement Decree of the Current Radio Act. The general conditions for the establishment of a radio station are as follows: first, the communication item should be suitable for the purpose of opening and the kind of the requesting radio station; second, the facility should operate itself; third, it is not in violation of laws and ordinances; At the same time, do not cause harm to people and property. In addition, special conditions are imposed on the experimental station, the amateur station, and the amateur station for relay purposes in accordance with the purpose of opening and using the station.

Procedures related to the establishment of a radio station are generally carried out in accordance with the following provisions, and the regulations related to the use of radio stations are applied after establishment.

\section{Pre- and Post-Regulation System of Radio Wave Management in Major Industrial Countries}

\subsection{Pre-Emptive Regulatory System for Radio Control of Major Industrial Countries}

Each country has a radio management system suitable for its own country in consideration of its legal, cultural and geographical characteristics for the efficient use of radio resources and the convenience of users. Commonly, it has radio control system of pre-regulation (virtuous circle structure) and post-regulation (post-circulation structure). Each country's pre- and post-regulations are as follows.

Countries with high population density and narrow geographical characteristics, such as Japan and South Korea, have a different radio management system than countries like the United States, which have a large land area and a low population density. Since radio waves are geographically and spatially limited, if radio stations are densely populated due to narrow geographical features such as Korea and Japan and high population density, direct radio control systems such as field inspections are established. In addition to the standards of radio management agencies, countries in a wide range of countries have their own standards or codes for the establishment of radio stations within the community community to manage the efficient propagation.

Example 1) In the case of US amateur radio stations, the amateur radio qualification examination system, which was under the supervision of the FCC1 since 1984, has started to be administered through the VEC2 system. In the days when the FCC was directly involved in the qualification tests, the test was conducted at 23 FCC regional offices nationwide. However, if there is a candidate residing at a distance of 125 miles or more from a regional office for one examinee.

Example 2) In the United States, there are about 500,000 civilian aircraft stations, while Korea has about 560 aircraft carriers. Fundamentally, there is a huge difference between the market, the worker, and the users, so the management system must be different. 
In ITU-R Recommendation SM 2130, "Inspection contributes to maintaining the responsibility of radio users to operate in a condition free of interference and interference, in order to increase the sense of responsibility and comply with national technical and administrative regulations" And the importance of inspection. Comparing only whether or not there is a radio station license / inspection system at the same level as that of South Korea without taking into consideration the circumstances of each country can be regarded as an error in analyzing only a fragmentary part without understanding the system properly. It is appropriate to compare the regulatory level and system of each country on the basis of the same purpose, such as prevention of interference, and the improvement point derived from this should be reviewed and supplemented.

\subsection{Us: Construction Permits, Coordination, Environmental Impact Assessment}

Establishment of a radio station, construction license, coordination, and environment assessment that are subject to pre-operation regulation.

The inspection work is carried out by the FCC's Enforcement Bureau (EB) and has four regional offices and 24 field offices. Field offices conduct regular field surveys, equipment inspections, radio equipment inspections, cable systems, antenna structures, and disaster assistance.

\subsection{Australia: Authorized Authorization Agency}

ACMA has a headquarters office and eight operation centers in four urban areas, and 81 employees are in charge of radio management. In addition to the ACMA, private licensees are allowed to perform all licensing and frequency license related licensing tasks with the accreditation system. Accredited Persons (APs), as of March, have 34 operators, which are related to the issuance of frequency allocation certificates (FACs) related to Apparatus Licenses on behalf of ACMA and the issuance of spectrum licenses (IICs) 4).

\subsection{UK: Pre-adjustment, Site Clearance, Pre-Approval}

In Ofcom, if a station is a Customized type, where there is concern about interference from other bands and frequencies, Coordination is implemented to prevent interference. In particular, the "Site Clearance or Coordination" is strictly enforced for the establishment of radio stations in public frequencies such as government and civil aviation. In the case of base stations of mobile communication operators, Pre-Approval of Regional Planning Agency (LPA)). The Regional Planning Agency will review the adverse effects of the establishment of radio stations, such as compliance with technical standards, environmental friendliness and common use, and the intensity of electromagnetic waves for 56 days, and approve the establishment of radio stations if the conditions are satisfied.

\subsection{Japan: Permission / Inspection System}

The Ministry of Internal Affairs and Communications is carrying out licensing, inspection and surveillance work in the Regional Comprehensive Communication Supervision Bureau of the Comprehensive Communication Infrastructure Bureau. (Regular, complete, and change inspections are carried out by "registered inspectors" (329 companies)). Technical conformity certification / construction design certification system is put in place, and the completion inspection is omitted and exempted for some radio stations. In Japan, more stringent regulations are applied than in Korea in order to protect human bodies and interferences. For example, in Japan, there is still a proof of cellular phone verification system deregulated in 2000 in Japan. Species define a part of the Radio Law and most of them are defined in the Enforcement Rules of the Radio Law. In Japan, there are 27 jobs and 48 stations. In particular, it should be noted that radio stations and 
services not specified in the current Radio Regulations are specified in the Enforcement Regulations of the Radio Regulations so that they can be specified separately.

\section{Advanced Radio Control System}

\subsection{Japan's Radio Management System}

Japan's radio control licensing system must obtain permission from the Ministry of Internal Affairs and Communications to establish a mobile radio station.

From the design and production stage, the base station equipment is managed by the certified company such as TELEC, and the radio quality is managed. The equipment proved to conform to the certification standard can be opened through a simple permission procedure.

The inspection system is similar to Korea, such as completion inspection, change inspection, and periodical inspection.

\subsection{UK Radio Control System}

Ofcom will be responsible for establishing radio communications stations in the UK, and the Environment Planning Agency (LPA37) is responsible for eco-friendly (steel towers, buildings, etc.) and electromagnetic waves.

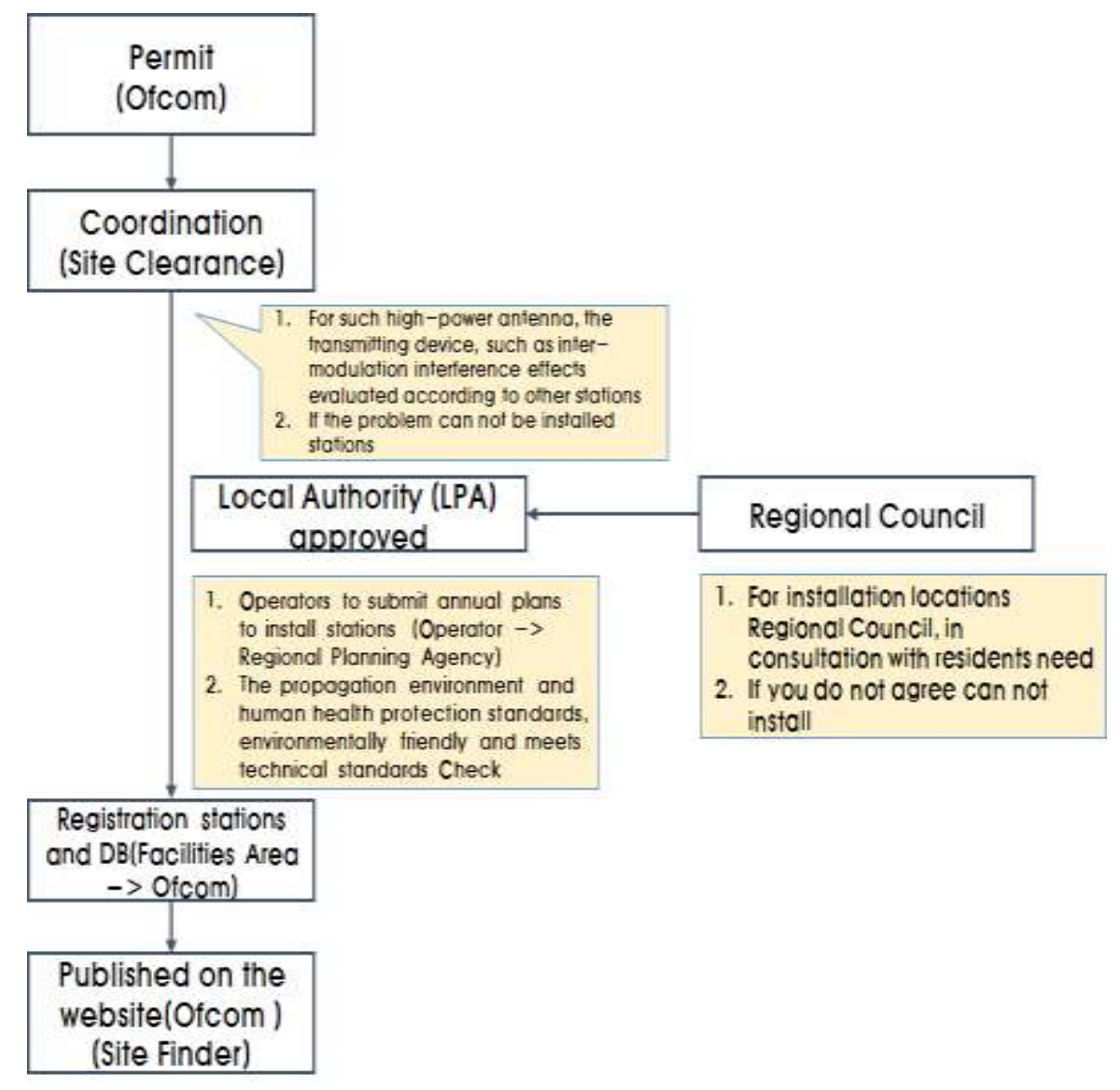

Figure 2. Mobile Operators Radio Station Licensing Procedures (England) 
Table 3. IPA Submit Your Request Prior Authorization

\begin{tabular}{|c|c|}
\hline Mandatory legal submissions & Other mandatory submissions \\
\hline $\begin{array}{l}\text { A written explanation of the } \\
\text { development plan } \\
\text { - Installation Site } \\
\text { - Radio equipment for local installation } \\
\text { or the owner of the certification scheme } \\
\text { notified renters } \\
\text { - When installing towers within } 3 \mathrm{~km} \\
\text { Civil Aviation Administration of } \\
\text { Airports (CCA), seojanggwan defense, } \\
\text { development planning advice from the } \\
\text { history of the airport operators } \\
\cdot \text { fees }\end{array}$ & $\begin{array}{l}\text { Before installing the new tower } \\
\text { existing towers, construct, building } \\
\text { utilization review } \\
\text { - If there is a need, purpose and unique } \\
\text { architectural plan } \\
\text { - schools (including universities) } \\
\text { established in the vicinity of the mobile } \\
\text { station, change, confrontation during the } \\
\text { school confirmed the relationship } \\
\text { agreement with the department } \\
\text { - ICNRP Directive Compliance } \\
\text { Certificate } \\
\text { - Plan to install the antenna height, } \\
\text { frequency, and modulation } \\
\text { characteristics and details of outputs }\end{array}$ \\
\hline
\end{tabular}

Radio Management Coordination will implement Site Clearance with radio stations of existing operators when establishing a radio station. Submission of plans for installation of radio stations to LPA at the end of each year at the end of each year and prior approval for construction of radio stations Apply. The LPA will review the application for 56 days and approve the construction of the operator station in consultation with interested organizations such as the residents' associations and the military commissions. The preapproval targets are (1) a tower of $15 \mathrm{~m}$ or more installed on the ground / building / (3) more than $2.5 \mathrm{~m} 2$ of radio equipment storage box, (4) protective equipment.

The Inspection System is designed to conduct on-site inspections in the case of radio interference caused by interferences, and it is possible to forecast the installation of radio stations through the establishment and approval of radio station installation plans annually, suggesting that the complaints can be resolved through consultation with the regional council.

Pre-coordination is possible through the Site Finder of the mobile communication service provider and the radio station information such as the facility, installation site, antenna height, frequency range, output power, and radio wave format is disclosed on the Ofcom homepage.

\subsection{American Radio Management System}

In order to establish a mobile radio station, the radio wave management approval procedure in the United States must submit the frequency coordination contents and the results of the environmental impact assessment to the FCC.

Modification and re-authorization are also handled in the same way as new permits. 


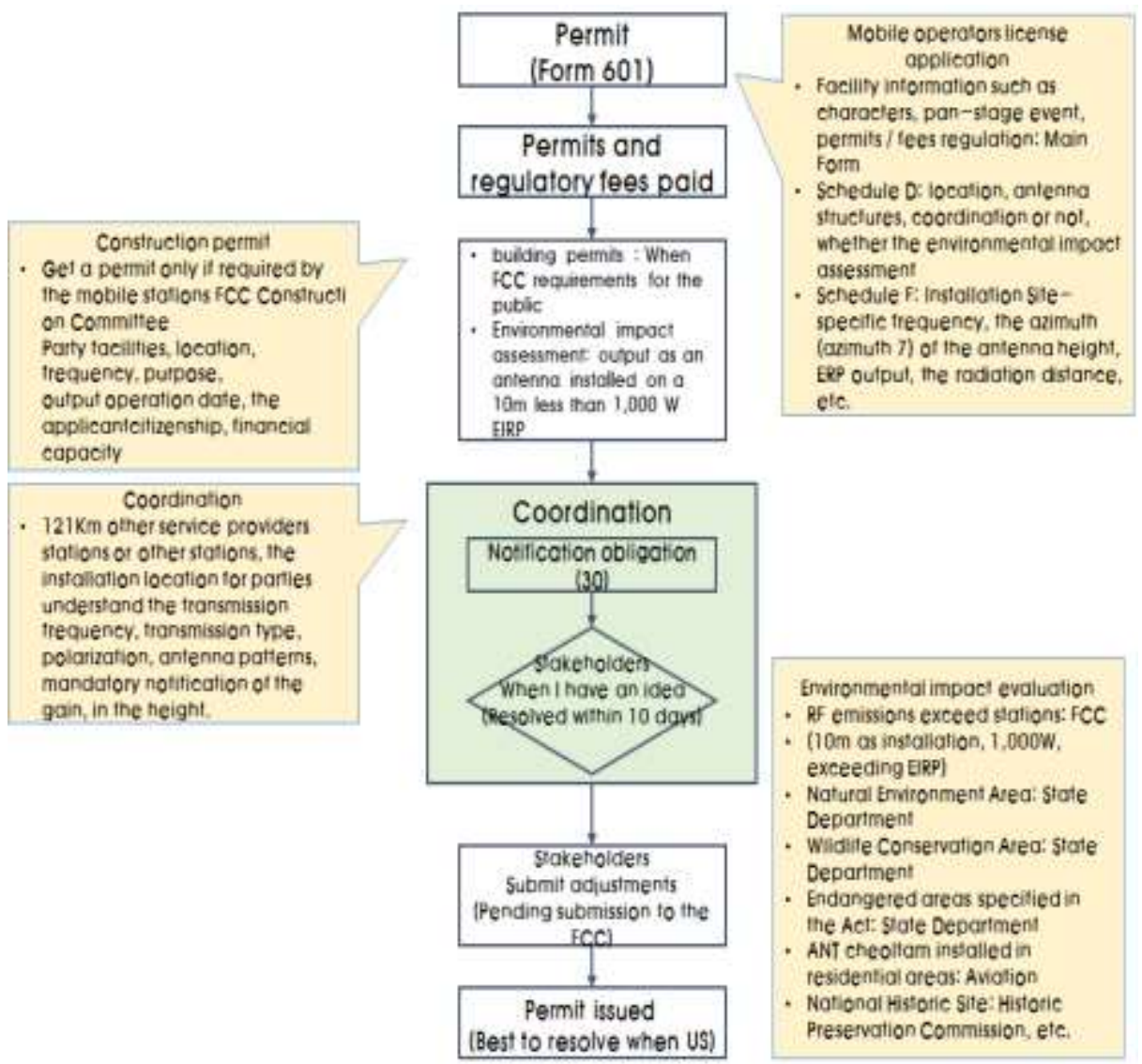

Figure 3. Mobile Operators Radio Station Licensing Procedures (USA)

Radio management coordination is to set parameters such as radio equipment output and antenna to minimize interference with other radio stations when a station is opened, changed, or reauthorized. Pattern gain, ground level and elevation.

The interference analysis is analyzed and adjusted to the FCC using the radio station DB and program provided by the FCC for 30 days during the mandatory notice period.

Environmental impact assessment is mandatory for stations with an output power of $1,000 \mathrm{~W}$ EIRP or higher installed at a distance of $10 \mathrm{~m}$ or less and submit the results of the EA 35. The results of radio stations (antennas, steel towers, radiated power, etc.) This is an evaluation system. When applying for permission, the FCC will submit an environmental impact assessment report. If it is converted to domestic standards, it is a radio station equivalent to $30 \sim 50 \mathrm{~W}$.

The inspection system is a similar inspection system and operates coordination and environmental impact assessment. In the United States, a reliable radio station information database is secured and released to the general public, suggesting formation of a basis for co-ordination. In the United States, the FCC is working on the measurement of electromagnetic intensity and the establishment of commonality and environmentfriendly installation in Korea, which requires more than 30 days of mandatory announcement period and regulator days.

\subsection{Australian Radio Regulations}

Australia's Radio Access Authorization Procedures In order to establish a mobile radio station, an interference certificate (IICs Interference Influence Certificates (IICs)) Must be submitted to ACMA and approved by the local council. Changes in frequency, power, radio facilities, etc. are also the same as the new licensing procedure. 


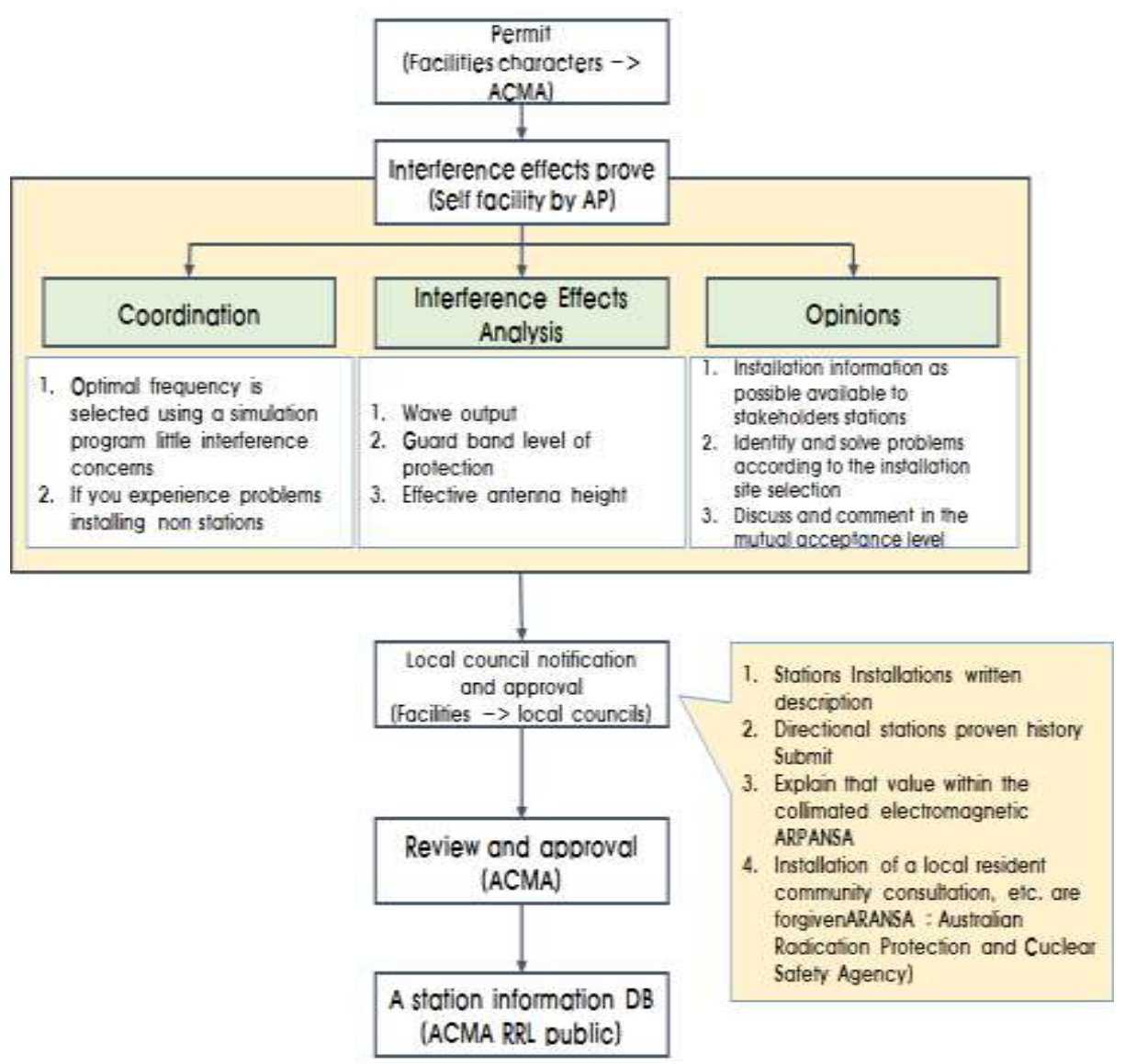

Figure 4. Mobile Operators Radio Station Licensing Procedures (Australia)

\section{Conclusion and Future Direction}

(RR Article 0.6), to secure the frequency of distress and safety purposes and to protect against harmful interference (RR Article 0.7), to prevent interferences and conflicts between countries, to promote the use of limited radio resources and geostationary satellites in a rational and equal manner (RR Article 0.8), promotion of efficient and effective operation of radio communication (RR Article 0.9), and establishment and regulation of new wireless communication technology application (RR Article 0.10).

Radio license permits all radio stations to operate without a license issued by the competent administration or government entrusted authority, and includes an obligation for inspection to ensure efficient management of radio resources (RR Article 18.1).

Inspection of a radio station shall comply with the technical characteristics of the radio station specified in the Radio Regulations, such as the frequency tolerance of the radio waves used by the station, the spurious emission power, the permissible power level, etc. in order to ensure the efficient use of the frequency (RR Article 3). Each country shall take measures to eliminate interference by minimizing power duplication, distress and interference with safety frequencies, occupied bandwidth and spurious emissions of all stations (RR Article 15).

Inspection of aircraft stations and ship stations in each country shall inspect the adequacy of radio installations and arrangements of radios for aircraft and ship stations (RR Articles 39 and 49). 


\section{References}

[1] W. Cho, H. Choi and H. Cho, "A study on integration scheme of wireless communications in railway wireless network", Journal of the Korea Institute of Electronic Communication Sciences, vol. 10, no. 9, (2015), pp. 659-664.

[2] G. Seok, "Study on the Receiver Performance in a Wireless Network using Turbo Code", Proceedings International Conferences, August 19-20, 2016, Harbin, China, vol.138, (NGCIT 2016), pp.34-37.

[3] Wireless Management, "Administrative prices charged for radio resource research institutions", Korea Communication Agency, (2004).

[4] Propagation Propagation salons Inspection Agency, "2013 Review Report Management System using radio waves", Korea Communication Agency, (2013).

[5] Propagation Propagation salons Inspection Agency, "2014 Review Report Management System using radio waves", Korea Communication Agency, (2013).

[6] Propagation Propagation salons Inspection Agency, "Licensing \& Inspection System for use at home and abroad propagation", Korea Communication Agency, (2012).

[7] Propagation Propagation salons Inspection Agency, "Studies measuring the communication quality of the digital communication system", Korea Communication Agency, (2013).

[8] Propagation Propagation salons Inspection Agency, "Study on improving radio station established procedures", Korea Communication Agency, (2012).

[9] Propagation Propagation salons Inspection Agency, "Licensed radio stations. Radio Waves Study on the test system”, Korea Communication Agency, (2014).

[10] Propagation Propagation salons Inspection Agency, "Anti-social dysfunction study of the propagation environment according to pre-deregulation", Korea Communication Agency, (2010).

[11] Y. Yeom, "Radio Broadcasting Act. System maintenance study", Korea Communication Agency, (2003).

[12] H. Lee, "Using radio waves resources development Management Study", KISDI, Information Society Development Institute, (2002).

[13] K. Cheo, "Study on the direction of the radio wave revised convergence era tongbang", Wireless Management, (2005).

[14] D. Park, "Recent Trends and Policy Implications of the radio control system", KISDI, Information Society Development Institute, (2003).

[15] C. Kin, "Frequency reallocation foreign policy case study", KISDI, Information Society Development Institute, (2004).

[16] H. Sin, "A study on The Role of Communication at Disaster Managing in Modern Societies", Journal of the Korea Institute of Electronic Communication Sciences, vol. 3, no. 1, (2008), pp. 31-38.

[17] H. Yeon and H. Sin, "A study on new radio wave law of system reorganization for korea", Journal of the Korea Institute of Electronic Communication Sciences, vol. 4, no. 1, (2009), pp. 1-6.

[18] H. Sin, "A Study on Radio Wave Law Revision Content for Korea", Journal of the Korea Institute of Electronic Communication Sciences, vol. 4, no. 3, (2009), pp. 176-182.

[19] H. Sin, "A study on South Korea's disaster safety of wireless communication", Journal of the Korea Institute of Electronic Communication Sciences, vol. 6, no. 1, (2011), pp. 1-5.

[20] H. Sin, "Domestic radio waves propagate management and control systems investigate the system status", Journal of the Korea Institute of Electronic Communication Sciences, vol. 11, no. 5, (2016), pp. 441-450.

[21] H. Sin, "Domestic radio waves propagate management and control systems investigate the system status", Journal of the Korea Institute of Electronic Communication Sciences, vol. 12, no. 1, (2017), pp. $1-8$.

This paper is a revised and expanded version of a paper entitled [Study on pre-post regulation of radio wave management in major developed countries] presented at [Proceedings International Conferences, August 16-18, 2017, Ho Chi Minh, Vietnam, NGCIT 


\section{Authors}

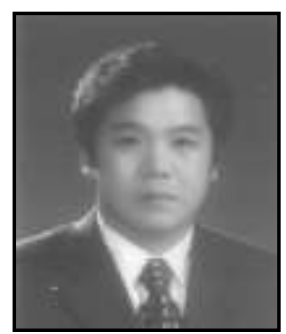

Sang-Ok Youn, he received his $\mathrm{PhD}$ degrees in Computer Science in 2005, and 2010, respectively, from the Honam University, Korea. He is currently as Project Manager in Ssangyong Software Co., Ltd.

His research interests include Data Communication Systems, Video system, Packet transmission system and Communication policy.

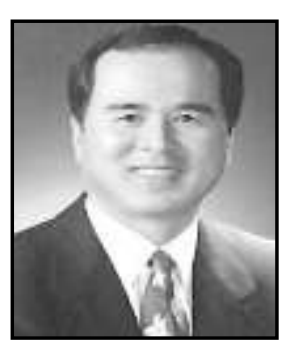

Hyun-Sik Shin, he received his $\mathrm{PhD}$ degrees in Communication policy in 1992, and 1995, respectively, from the Kyungnam University, Korea. He joined Chunnam National University, where he is currently as professor in the department of Department of Electronic Communication Engineering. His research interests include Data Communication Systems, Maritime communication, Disaster communication and Communication policy. 